\title{
HIV/AIDS epidemic features and trends in setif city (Algeria) from 1986 to 2009
}

\author{
Amel Ouyahia*, Mounira Rais, Abdelkader Gasmi, Wahiba Guenifi, Salah Mechakra, Abdemadjid Lacheheb \\ From $16^{\text {th }}$ International Symposium on HIV and Emerging Infectious Diseases \\ Marseille, France. 24-26 March 2010
}

\section{Background}

To identify the epidemiologic characteristics of HIV and AIDS in SETIF during the period between 1986, and 2009.

\section{Methods}

This report presents a descriptive analysis of HIV and AIDS surveillance data. The subjects of this study were all notified HIV and AIDS cases in SETIF diagnosed by ELISA and confirmatory Western blot, we worked with epi info 3.5.2.

\section{Results}

The HIV epidemic started in SETIF in 1986 with the first diagnosed AIDS cases. The number of cases slowly but steadily increased, to reach, by 2009,152 cases. The median age of infected persons was 39,77 years. $40.8 \%$ were WOMEN; The most frequent mode of transmission is sexual $(76,9 \%$ of all cases; with mainly heterosexual transmission 77.9 percnt; with a strong correlation to travel and migration $37.20 \%$ ). the proportion of persons diagnosed late (within 12 months before AIDS diagnosis) was $82,3 \%$; $91.4 \%$ of married men (36) have sexual relationships outside marriage as compared to $0.0 \%$ of married women(27). We report also $13.60 \%$ discordant couples among married patients, Among documented HIV-positive mothers (36), their children were screend in $61.10 \%$, and $95.5 \%$ of them were seronegatif, $55,9 \%$ of all cases were treated with ARV. HIV/ AIDS deaths $36,2 \%$ decreased markedly from 2002, associated with the advent of HAART.

\section{Discussion}

Gender distribution and distribution by mode of transmission among HIV-infected revealed an equal gender distribution of infection wich contrary to sub-Saharan Africa, where women are more affected.

* Correspondence: ouyahiaam@yahoo.fr

Faculte De Medecine Centre Hospitalo Universitaire, Setif, Algeria a higher female prevalence of HIV infection might be expected in algeria since heterosexuality is the prevailing mode of sexual transmission.

Non-marital sex is the main risk factor, as it is worldwide for several reasons:

Our data might be explained by

$\ddot{u}$ the large number of males who travel to other countries, especially to areas with a high prevalence of HIV infection. Travel and tourism enhance the probability of having casual sex, a fact that increases the risk of exposure to sexually transmitted infections

$\ddot{u}$ The ever-decreasing religious values

Adults 23- to 45-years old were found to constitute $65,8 \%$ of all cases, a fact that points to the serious social and economical impact of the disease

The trend of mode of transmission by blood transfusion shows that most of the cases infected through contaminated blood were registered before 1995. These patients most probably received blood unscreened for HIV in the 1980s before blood safety measures were undertaken. However, the incidence of this type of transmission significantly declined after implementation of blood safety policies.

$32,90 \%$ of infected had died, This high percentage can be explained by the fact that:

most infections are detected among patients, who already have a bad prognosis $66,40 \%$

$68,6 \%$ of death occurs before 1996 it means before the introduction of highly active antiretroviral therapy.

Published: 11 May 2010

doi:10.1186/1742-4690-7-S1-P99

Cite this article as: Ouyahia et al:: HIV/AIDS epidemic features and trends in setif city (Algeria) from 1986 to 2009. Retrovirology 20107 (Suppl 1):P99. 